\title{
Health related quality of life among haemodialysis and kidney transplant recipients from Nepal: a cross sectional study using WHOQOL-BREF
}

\author{
Kamal Ranabhat ${ }^{1,2}$, Pratik Khanal ${ }^{2^{*}}$ (D), Shiva Raj Mishra ${ }^{3}$, Anu Khanal $^{2}$, Sangita Tripathi ${ }^{2}$ and Mahesh Raj Sigdel ${ }^{2}$
}

\begin{abstract}
Background: Very less is known about health-related quality of life (HRQOL) among patients with kidney diseases in Nepal. This study examined HRQOL among haemodialysis and kidney transplant recipients in Nepal.

Methods: The Nepali version of World Health Organization Quality of Life Instruments -(WHOQOL-BREF) questionnaire was administered using face to face interviews among end stage renal disease (ESRD) patients, from two large national referral centers in Nepal. The differences in socio-demographic characteristics among ESRD patients were examined using the Chi-square test. The group differences in quality of life (QOL) were examined using the Mann-Whitney $U$ test and Kruskal-Wallis tests.

Results: Of the 161 participants, 92 (57.1\%) were renal transplant recipients and 69 (42.9\%) patients were on maintenance haemodialysis. Hypertension (70.9\%) was the most common co-morbidity among ESRD patients. Haemodialysis patients scored significantly lower than the transplant recipients in all four domains as well as in overall perception of quality of life and general health. Ethnicity $(p=0.020)$, socio-economic status $(p<0.001)$, educational status $(p<0.001)$ and employment status $(p=0.009)$ were significantly associated with the overall QOL in ESRD patients. Across patient groups, educational status $(p=0.012)$ was positively associated with $\mathrm{QOL}$ in dialysis patients, while urban residence $(p=0.023)$, higher socio-economic status $(p<0.001)$, higher educational status $(p=$ $0.004)$ and diabetes status $(p=0.010)$ were significantly associated with better QOL in transplant recipients.

Conclusion: The overall QOL of the renal transplant recipients was higher than that of the patients on maintenance haemodialysis; this was true in all four domains of the WHOQOL-BREF. ESRD patients with low HRQOL could benefit from targeted risk modification intervention.
\end{abstract}

Keywords: Kidney, Nepal, End stage renal disease, Quality of life, haemodialysis, transplant

\section{Background}

The incidence and prevalence of end-stage renal disease (ESRD) has been rising globally, yet the burden in South Asia is not known precisely due to improper registration systems [1]. A population-based study assessed the age-

* Correspondence: pratikkhanal@iom.edu.np

${ }^{2}$ Institute of Medicine, Tribhuvan University, Kathmandu, Nepal

Full list of author information is available at the end of the article adjusted incidence of ESRD at 232 cases per million populations per year in India [2]. In Nepal, the estimated incidence of ESRD is approximately 2900/year [3, 4].

ESRD is an increasingly recognized pandemic that is associated with high cost and financial burden to patients, families and the health system of any country [5-7]. In Nepal, the burden of ESRD is growing, however only a fraction of ESRD patients receive renal replacement

(c) The Author(s). 2020 Open Access This article is licensed under a Creative Commons Attribution 4.0 International License, which permits use, sharing, adaptation, distribution and reproduction in any medium or format, as long as you give appropriate credit to the original author(s) and the source, provide a link to the Creative Commons licence, and indicate if changes were made. The images or other third party material in this article are included in the article's Creative Commons licence, unless indicated otherwise in a credit line to the material. If material is not included in the article's Creative Commons licence and your intended use is not permitted by statutory regulation or exceeds the permitted use, you will need to obtain permission directly from the copyright holder. To view a copy of this licence, visit http://creativecommons.org/licenses/by/4.0/ The Creative Commons Public Domain Dedication waiver (http://creativecommons.org/publicdomain/zero/1.0/) applies to the data made available in this article, unless otherwise stated in a credit line to the data. 
therapy every year [8]. ESRD treatment is costly and unaffordable for most Nepalese people, although the Government of Nepal provides payment to the hospital to cover some cost for haemodialysis and transplant recipients $[3,9,10]$. Infrequent and inadequate haemodialysis along with malnutrition and frequent use of blood transfusion are some of the major problems prevailing in Nepalese haemodialysis patients [11-13]; at the same time, expenses of the post-transplant medicines and distance to travel for regular follow up apparently affect the kidney transplant recipients [9]. Naturally, the quality of life (QOL) of ESRD patients on maintenance haemodialysis and kidney transplant recipients is compromised impacting various health outcomes $[14,15]$.

Assessment of QOL could be a valuable research tool in assessing the outcome of therapeutic intervention in chronic diseases [16-18]. The World Health Organisation (WHO) has defined QOL as an individual's perceptions of their position in life in the context of the culture and value systems where they live and in relation to their goals, expectations, standards and concerns [16]. Globally, health related quality of life (HRQOL) has been recognized as an important tool in the assessment of the health and wellbeing of people receiving renal replacement therapies (RRT) [19-21].

Although kidney transplantation was legalised in 2002, the first successful live donor kidney transplantation was performed in Tribhuvan University Teaching Hospital (TUTH) in 2008 [22, 23]. There are currently 42 haemodialysis and five transplant centers in Nepal for its 30 million people. All five transplant centers and 17 out of 42 haemodialysis centers are situated in the Kathmandu valley, the capital city of the country [24]. A paucity of information on the QOL among patients attending ESRD services exists in Nepal. Furthermore, limited studies are available to compare QOL in ESRD patients receiving different RRTs. In this context, this study aimed to assess and compare the QOL of haemodialysis and renal transplant recipients in various dimensions using WHOQOL BREF. We expect that the current study will support policymakers and concerned authorities in developing better interventions and programs for ESRD patients in Nepal.

\section{Methods}

\section{Study settings}

The study was conducted in haemodialysis patients attending TUTH and renal transplant recipients attending the National Public Health Laboratory (NPHL) under the Ministry of Health and Population (MoHP). The patients who underwent renal transplant visited NPHL for the purpose of monitoring kidney function tests and other labs as part of their follow-up. Both of these institutions are situated in Kathmandu, the capital city of Nepal.

\section{Study design and sampling technique}

A cross-sectional comparative study design was adopted to assess the HRQOL between haemodialysis and renal transplant recipients. The NPHL was chosen for recruiting renal transplant recipients, while TUTH was chosen for recruiting haemodialysis patients for face-to-face interviews.

A total of 182 patients were approached for data collection of which 161 patients were recruited from the study sites in October and November in 2018. Coordination with the officials of the Department of Nephrology in TUTH and chronic kidney disease (CKD) service unit overseeing impoverishment citizen funds of NPHL was performed before approaching the study participants. All patients meeting the eligibility criteria during the data collection period were recruited as study participants. The eligibility for haemodialysis patients included those receiving haemodialysis at least twice a week for three months or more while for transplant recipients included those who were at least six months post kidney transplantation. Other eligibility for the study participants were those at least 18 years of age and were able to provide written consent. A total of 21 patients who had serious health complications and mental health disorders such as advanced liver failure, advanced heart failure, advanced respiratory problems, history of stroke affecting self-care and movement, and advanced dementia were excluded from the study because these conditions were expected to hamper the HRQOL of the patients. Similarly, those on peritoneal dialysis were not included since very few patients from TUTH are on peritoneal dialysis as RRT.

\section{Data collection measures}

The questionnaire comprised three sections. These included (i) socio-demographic information; (ii) information related to kidney disease and (iii) HRQOL of the study participants. The World Health Organization Quality of Life Instruments (WHOQOL-BREF), a generic health- related questionnaire developed by the WHOQOL group was selected to quantify the HRQOL of ESRD patients [25]. The Nepali version of the WHOQOL-BREF questionnaire has been used in crosscultural settings by Giri et al. [26] and Mishra et al. [27]. The WHOQOL-BREF consists of 26 items and provides a profile of scores on four dimensions of quality of life: physical health, psychological health, social relationships and environment health domain as well as two generic questions on overall perception of QOL and general health. The scores in the four domains were the outcome variables while all other variables were considered independent variables. Higher scores represented better quality of life. The scores on the $26^{-}$item questions were measured on a scale of 4-20 [25]. 
The socio-demographic information included age (continuous; 20-30, 31-40, 41-50, > 50 years), sex (male and female), residence (urban and rural), socio-economic status (lower, middle and upper), ethnic group (Brahmin/ Chhetri, Janajati and others), marital status (ever married, unmarried), employment (unemployed and employed), education (illiterate, up to 10 years of schooling and higher education), food habit (vegetarian and non-vegetarian) and perceived family support (full, partial and no support). Residence was considered as rural if the participant belonged to rural municipality and urban if residing in municipality, sub-metropolitan city and metropolitan city. The socio-economic status of the study participants was measured using "Kuppuswamy's socio-economic status scale for Nepal [28]. It is measured on the basis of literacy level, type of occupation and family income level per month. This tool was developed in India in 2009 in which socioeconomic status is identified based on total score: 26-29 score for upper level, (b) 16-25 score for upper middle, (c) 11-15 score for lower middle, (d) 5-10 score for upper lower and (e) $<5$ score for lower level. In this study, the upper middle and lower middle were merged as the middle while the upper lower and lower were merged as the lower. Similarly, clinical information related to ESRD included donor for transplant, duration of dialysis or transplant and presence of comorbidity (hypertension, diabetes, nephritic syndrome, others).

\section{Data collection procedure}

Data were collected by face to face interviews. Four research assistants (public health undergraduates) along with the first author were involved in the interviews at the study sites. The research assistants were personally briefed and trained by the first author beforehand. Pre-testing of tools was carried out among five dialysis and five transplant recipients attending Bir Hospital located in Kathmandu. Based on pre-testing, minor changes in wording and sequence of the questions were made. Cronbach's alpha test was computed for each domain and the value ranged from 0.60 to 0.86 indicating good internal consistency. Ethical approval for the study was obtained from the Ethical Review Board of the Nepal Health Research Council (Reference number: 389/2016), and administrative approval was taken from data collection sites. Prior written informed consent was obtained from the participants or their primary relatives, whichever applicable.

\section{Data analysis}

The data were entered in EpiData version 3.1 and the data were transported to IBM SPSS version 21.0 for analysis. Descriptive analysis included calculation of frequency, percentage, mean and median for presentation of socio-demographic, ESRD-related and WHOQOLBREF scores. The chi-square test was used to assess differences in categorical variables while the Mann-
Whitney $U$ test and Kruskal-Wallis one-way analysis of variance tests were used to compare QOL across sociodemographic and clinical characteristics since the QOL score was not normally distributed. The level of significance was maintained at 5\% with $p<0.05$ considered statistically significant.

\section{Results}

\section{Demographic characteristics of the study participants}

Among 161 participants, 92 (57.1\%) were kidney transplant recipients and the remaining 69 (42.9\%) were haemodialysis patients. In this study, $54.7 \%$ were $18-40$ years of age, $75.2 \%$ were male and $47.3 \%$ belonged to the Aadibasi/Janajati ethnic group. The mean age $( \pm$ SD) of the study participants was $40.66 \pm 12.02$ years. Most of the participants $(58.4 \%)$ belonged to middle socioeconomic status, $12.4 \%$ were illiterate and $50.3 \%$ were unemployed. Nearly two-thirds (65.8\%) of the participants received full support from their family in care and psychological support, while one in ten participants did not receive any support from their family (Table 1 ).

The age of the patients in the dialysis group was significantly higher than that in the transplant group $(p<$ 0.01 ), and there was a significant difference in education status $(p=0.021)$ and employment status $(p=0.020)$ across the two patient groups. However, there was no significant difference according to sex, residence, socioeconomic status, ethnic group, marital status or perceived family support in the patient groups (Table 1). Patients with renal transplant received kidney donation mainly from their parents $(31.5 \%)$, spouse $(30.4 \%)$ and children (25.0\%). The duration of renal replacement therapy was more than one year for $67.4 \%$ of the renal transplant recipients and $53.4 \%$ for the dialysis patients. Regarding comorbidities, $77.0 \%$ had hypertension, $20.5 \%$ had diabetes mellitus, $5 \%$ had nephrotic syndrome, and $6.2 \%$ had other comorbidities.

\section{WHOQOL-BREF scores of dialysis and renal transplant recipients}

Table 2 shows the mean score for QOL in different domains of the WHOQOL-BREF. The highest mean score for QOL was found in the social relationship $(13.58 \pm 2.14)$ domain, and the lowest mean score was found in the environmental health domain (11.73 \pm 1.89). Haemodialysis patients scored significantly lower than the transplant recipients in terms of physical $(p<0.001)$, psychological $(\mathrm{p}<0.001)$, social relationship $(p=0.012)$ and environmental health $(p=$ $0.004)$ domains. Similarly, the overall QOL score $(p<$ $0.001)$, overall perception of quality of life, Q1 $(p<$ $0.001)$ and overall perception of general health, Q2 $(\mathrm{p}<0.001)$ were significantly lower in haemodialysis participants than in transplant recipients $(\mathrm{p}<0.001)$. 
Table 1 Socio-demographic characteristics of the study participants $(n=161)$

\begin{tabular}{|c|c|c|c|c|}
\hline Characteristics & $\begin{array}{l}\text { Total }(n=161) \\
n(\%)\end{array}$ & $\begin{array}{l}\text { Dialysis }(n=69) \\
n(\%)\end{array}$ & $\begin{array}{l}\text { Transplant }(n=92) \\
\mathrm{n}(\%)\end{array}$ & $P$-value \\
\hline Age (years) & $(40.66 \pm 12.02)$ & $43.57 \pm 13.02$ & $38.47 \pm 10.77$ & $<0.01$ \\
\hline $20-30$ & $36(22.4)$ & $14(20.3)$ & $22(23.9)$ & \\
\hline $31-40$ & $52(32.3)$ & $17(24.6)$ & $35(38.0)$ & \\
\hline $41-50$ & $40(24.8)$ & $15(21.7)$ & $25(27.2)$ & \\
\hline$>50$ & $33(20.5)$ & $23(33.3)$ & $10(10.9)$ & \\
\hline Sex & & & & 0.958 \\
\hline Male & $121(75.2)$ & $52(75.4)$ & $69(75.0)$ & \\
\hline Female & $40(24.8)$ & $17(24.6)$ & $23(25.0)$ & \\
\hline Residence & & & & 0.234 \\
\hline Urban & $124(77.0)$ & $50(72.5)$ & $74(80.4)$ & \\
\hline Rural & $37(23.0)$ & $19(27.5)$ & 18 (19.6) & \\
\hline Socioeconomic status & & & & 0.061 \\
\hline Lower & $57(35.4)$ & $31(44.9)$ & $26(28.3)$ & \\
\hline Middle & $94(58.4)$ & $33(47.8)$ & $61(66.3)$ & \\
\hline Upper & $10(6.2)$ & $5(7.2)$ & $5(5.4)$ & \\
\hline Ethnic group & & & & 0.203 \\
\hline Brahmin/ Chhetri & $57(35.4)$ & $21(30.4)$ & $36(39.1)$ & \\
\hline Aadibashi/Janajati & $76(47.2)$ & $32(46.4)$ & $44(47.8)$ & \\
\hline Others & $28(17.4)$ & $16(23.2)$ & $12(13.0)$ & \\
\hline Marital status & & & & 0.652 \\
\hline Unmarried & $11(6.8)$ & $4(5.8)$ & $7(7.6)$ & \\
\hline Ever married & $150(93.2)$ & $65(94.2)$ & $85(92.4)$ & \\
\hline Employment & & & & 0.020 \\
\hline Employed & $80(49.7)$ & $27(39.1)$ & $53(57.6)$ & \\
\hline Unemployed & $81(50.3)$ & $42(60.1)$ & $39(42.4)$ & \\
\hline Education & & & & 0.021 \\
\hline Illiterate & $20(12.4)$ & $14(20.3)$ & $6(6.5)$ & \\
\hline Up to 10 years of schooling & $96(59.6)$ & $40(58.0)$ & $56(60.9)$ & \\
\hline Higher & $45(28.0)$ & $15(21.7)$ & $30(32.6)$ & \\
\hline Food habit & & & & 0.719 \\
\hline Vegetarian & $6(3.7)$ & $3(3.3)$ & $3(4.7)$ & \\
\hline Non vegetarian & $155(96.3)$ & $66(96.7)$ & $89(95.3)$ & \\
\hline Family support & & & & 0.513 \\
\hline Full & $106(65.8)$ & $42(60.9)$ & $64(69.6)$ & \\
\hline Partial & $39(24.2)$ & $19(27.5)$ & $20(21.7)$ & \\
\hline No support & $16(9.9)$ & $8(11.6)$ & $8(8.7)$ & \\
\hline
\end{tabular}

\section{Socio-demographic variables, ESRD characteristics and}

\section{QOL score}

The mean QOL scores across socio-demographic and ESRD characteristics are presented in Fig. 1. Ethnicity $(p=0.020)$, socio-economic status $(p<0.001)$, employment $(p=0.009)$ and education $(\mathrm{p}<0.001)$ of the ESRD patients were significantly associated with the overall QOL (Additional file 1). Among ethnic groups,
Aadibasi/Janajati had higher QOL than Brahmin/Chhetri and other ethnic groups. The QOL increased with the increase in socio-economic gradient and educational status. Age, sex, residence, marital status, hypertension and diabetes status were however not significantly associated $(p>0.05)$ with QOL among ESRD patients.

The mean differences in QOL scores were also assessed across haemodialysis and transplant recipients. 
Table 2 Mean domain score for haemodialysis and renal transplant recipients

\begin{tabular}{|c|c|c|c|c|}
\hline Type of domain & Total $(n=161)$ & Dialysis $(n=69)$ & Transplant $(n=92)$ & $P$-value \\
\hline Physical & $12.03 \pm 2.16$ & $10.61 \pm 1.99$ & $13.09 \pm 1.61$ & $<0.001$ \\
\hline Psychological & $12.38 \pm 2.44$ & $10.84 \pm 1.95$ & $13.53 \pm 2.12$ & $<0.001$ \\
\hline Social relationship & $13.58 \pm 2.14$ & $13.15 \pm 2.10$ & $13.89 \pm 2.13$ & 0.012 \\
\hline Environment health & $11.73 \pm 1.89$ & $11.25 \pm 1.62$ & $12.10 \pm 2.00$ & 0.004 \\
\hline Perception of quality of life & $3.03 \pm 0.90$ & $2.42 \pm 0.72$ & $3.49 \pm 0.73$ & $<0.001$ \\
\hline Perception of general health & $3.07 \pm 0.94$ & $2.51 \pm 0.80$ & $3.49 \pm 0.81$ & $<0.001$ \\
\hline Overall QOL score & $12.43 \pm 1.63$ & $11.46 \pm 1.35$ & $13.15 \pm 1.45$ & $<0.001$ \\
\hline
\end{tabular}

The findings showed that there was a statistically significant difference in QOL among haemodialysis and transplant recipients across socio-demographic and clinical characteristics $(p<0.05)$ with higher QOL scores in transplant recipients than in haemodialysis patients (Fig. 1, \& Additional file 1). Among haemodialysis patients, there was significant difference in QOL across educational status $(p=0.012)$, where those with higher educational status had a higher QOL. In the case of transplant recipients, urban residence $(p=0.023)$, higher socio-economic status $(p<0.001)$, higher education $(p=0.004)$ and diabetes status $(p=0.010)$ was significantly associated with better QOL (Fig. 1, \& Additional file 1). Similarly, higher socioeconomic status and higher educational status of the study participants were significantly associated with better QOL in all domains (Additional file 1).

\section{Discussion}

Quality of life is being increasingly recognized as one of the key outcome parameters in any medical and interventional treatment. To our knowledge, this is one of the few studies to report a comparison of QOL between haemodialysis and renal transplant patients in Nepal. The study findings revealed significantly higher QOL scores in transplant recipients than in haemodialysis patients across all domains: physical, psychological, social relationships and environmental health. Similarly, the overall perception regarding QOL and general health was also significantly higher in transplant recipients than in haemodialysis patients. A study from Nepal using the same tool in 2011 showed significantly higher QOL among transplant recipients compared to haemodialysis patients in the physical, psychological and social relationship but not in the environment health domain [29]. Previous studies conducted elsewhere have also shown impaired QOL in haemodialysis patients as compared to transplant recipients $[8,30-34]$. Although our study findings reinforce renal transplant as an effective RRT for improving QOL among people with ESRD, the health system in Nepal faces limited and inequitable access to transplant services. Furthermore, few nephrologists, long waiting times to receive transplant services and inadequate financial support add much to worry for people with ESRD [35].
The lower QOL in the physical domain in haemodialysis patients than in transplant recipients can be attributed to physical pain, weakness, insomnia and hindrance to daily activities as identified in previous studies [36, 37]. An earlier study from Nepal also showed an increased duration of haemodialysis as a negative predictor of QOL [38]. Similarly, the reason for renal transplant recipients having a higher QOL in the psychological domain might be due to a decrease in mental burden resulting from having to visit health facilities for frequent dialysis. Additionally, the increased self-esteem and improved perception regarding own health might have contributed to good mental wellbeing among renal transplant recipients [8]. Haemodialysis patients often face mental health problems due to their health conditions which might lead to a compromised QOL as identified by previous studies [37, 39, 40]. Renal transplant recipients had a higher QOL in the social domain than the haemodialysis patients in our study. This might be due to improved health including sexual relationships, and more leisure time, allowing them to network with their family and friends. Expensive treatment mainly drugs, difficulty in transportation during follow up and safety related issues might be contributing factors to the lower QOL score in the environmental domain among haemodialysis patients as compared to transplant recipients. The government pays hospitals a fixed amount for providing haemodialysis and transplant services for the destitute through its impoverished citizen fund established in 201 6[24, 35]. However, in the absence of renal registry and a fully viable health insurance system to cover expenses associated with the treatment, patients with ESRD face a major setback in living a quality life [35, 41]. Importantly, the government subsidy through the impoverished citizen fund does not cover all treatment expenses and moreover, there is a low enrollment and limited ceiling in benefit package (NPR $100,000)$ in health insurance [42]. In our study, even after transplant, QOL in the environmental health domain was found to be comparatively lower than that in other domains in renal transplant recipients. A social heath protection mechanism is thus imperative to address the financial barriers not only in seeking transplant services, but also saving people with chronic diseases in falling into the poverty trap. 


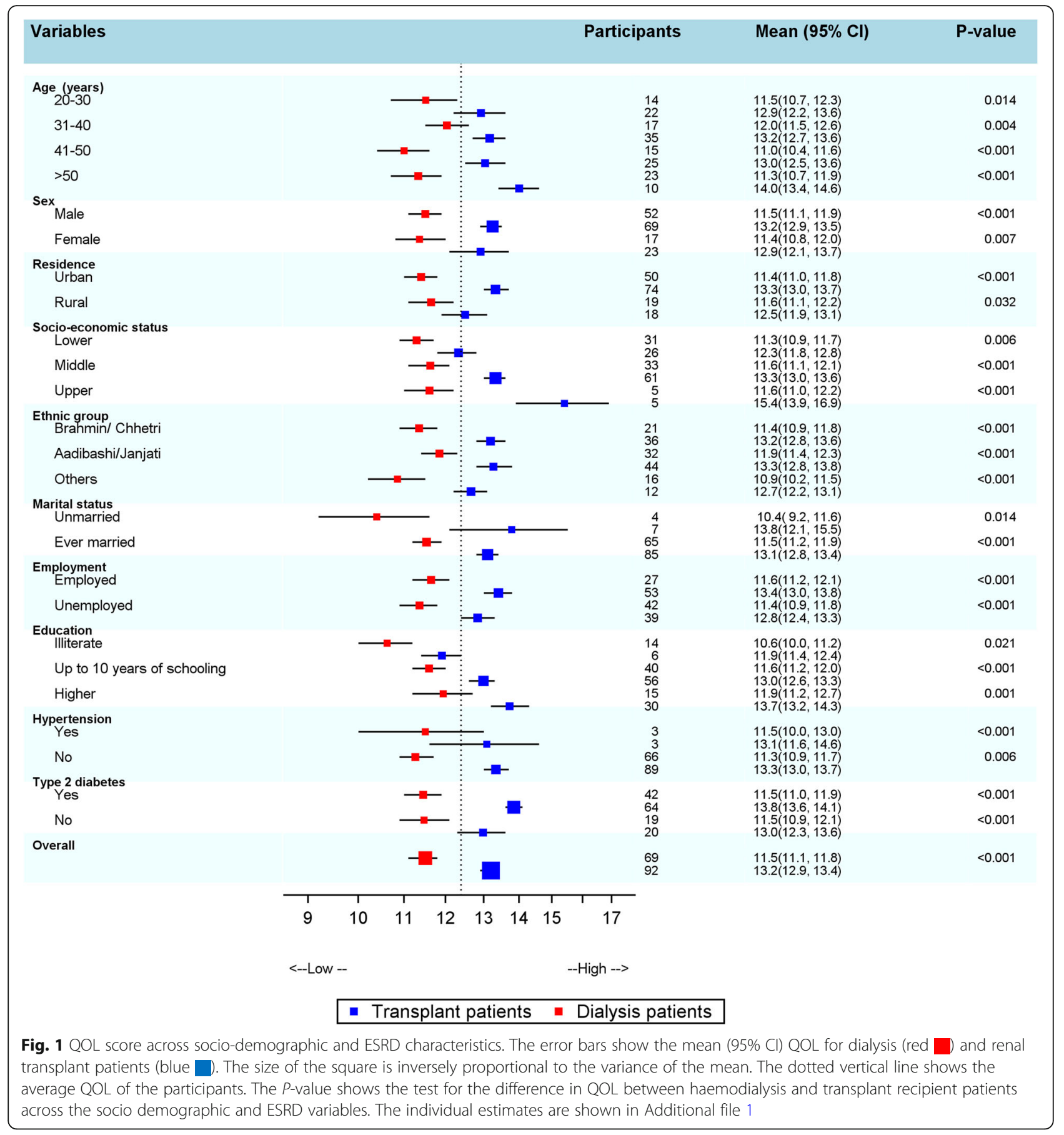

In this study, socio-economic status was positively associated with the overall QOL score among ESRD patients. Among patient groups, there was a significant difference in QOL across socio-economic status in transplant recipients. As people with higher socio-economic status are in a better position to pay for treatment expenses, it might have resulted in higher QOL. However, this was not the case among haemodialysis patients which indicates that haemodialysis patients have a poor QOL regardless of their socio-economic status.
Employment status was associated with overall QOL among ESRD patients. Nepal has a large informal economy, a quarter of the population under the poverty line, and the majority of the population under poverty either sell their assets for paying for health care especially for the treatment of chronic diseases or simply stop their treatment [43, 44]. Those employed are more likely to be in a better paying capacity for their health care than the unemployed and face less financial catastrophe and possibly higher QOL. 
This study has few strengths and limitations. In this study, WHOQOL-BREF tool was used to assess QOL which has been extensively used across different segments of the population in Nepal and globally, which makes it relevant for this study. One of the limitations of this study was that it sought to compare the HRQOL between only two categories of patients i.e. haemodialysis and transplant recipients and not with peritoneal dialysis and healthy populations, and such comparisons were done in a small sample of the population with differences in patient characteristics such as in age, education and employment. Moreover, the study might have encountered respondent bias due to subjective response and interviewer bias due to the first author's involvement in interviewing the study participants. Additionally, the study participants were mostly male in this study which might be due to the higher burden of CKD in male than female in Nepal as per the national study [45]. Moreover, this might also indicate inequity in service utilization for renal replacement therapy [13]. Further studies employing a large sample and qualitative study to explore the in-depth experience of people with ESRD might help to generate more robust evidence regarding QOL in this population. Despite limitations, this study provides a comparative situation of QOL faced by haemodialysis and transplant recipients and the evidence could be useful for policy makers, program managers and other stakeholders for developing an effective response towards improving the health conditions of people with ESRD. Considering the increasing burden of CKD as well as other non-communicable diseases in Nepal, it would be effective to design interventions for the reduction of behavioral, biological and environmental risk factors associated with chronic disease outcomes.

\section{Conclusion}

In summary, the QOL scores of renal transplant recipients were significantly better than those of haemodialysis patients in all four domains of the WHOQOL-BREF. Ethnicity, socio-economic status, educational status and employment status were significantly associated with the overall QOL in ESRD patients. Across patient groups, QOL improved significantly with an increase in socioeconomic status in transplant recipients while socioeconomic status was not associated with QOL in haemodialysis patients. Renal transplant services should be encouraged for people with ESRD with strong social health security mechanism, as renal transplant recipients have a higher QOL than haemodialysis patients.

\section{Supplementary information}

Supplementary information accompanies this paper at https://doi.org/10. 1186/s12882-020-02085-0.

Additional file 1.

\section{Abbreviations}

Cl: Confidence interval; CKD: chronic kidney diseases; ESRD: End stage renal disease; HRQOL: Health related quality of life; IOM: Institute of Medicine; MoHP: Ministry of Health and Population; NPHL: National Public Health Laboratory; QOL: Quality of life; RRT: Renal replacement therapy; SD: Standard deviation; TUTH: Tribhuvan University Teaching Hospital; WHO: World Health Organization

\section{Acknowledgements}

The authors would like to acknowledge all the study participants and research assistants who were involved in the data collection.

\section{Authors' contributions}

KR conceived the concept and design of the study. KR, AK and ST conducted the survey. KR and PK were involved in data analysis and manuscript writing. SRM and MRS supervised the study and critically reviewed the manuscript. All the authors read, reviewed and read the final manuscript. The author(s) read and approved the final manuscript.

\section{Funding}

None.

\section{Availability of data and materials}

All data related to this study are included in the manuscript and additional file.

Ethics approval and consent to participate

Ethical approval for this study was provided by the Nepal Health Research Council, Kathmandu, Nepal (Reference number: 389/2016). Written informed consent was obtained from individual participants. Confidentiality and anonymity of the participants were ensured by coding the interviews. Study participants were informed clearly about their freedom to opt out of the study at any point of time without justifying for doing so.

Consent for publication

Not applicable.

\section{Competing interests}

The authors declare that they have no competing interests.

\section{Author details}

'Department of Health Services, Ministry of Health and Population, Kathmandu, Nepal. ${ }^{2}$ Institute of Medicine, Tribhuvan University, Kathmandu, Nepal. ${ }^{3}$ World Heart Federation, Geneva, Switzerland.

Received: 22 June 2020 Accepted: 2 October 2020

Published online: 12 October 2020

\section{References}

1. Jha V. Current status of end-stage renal disease care in South Asia. Ethn Dis, 2009;19(S1):27-32

2. Modi G, Jha $V$. The incidence of end-stage renal disease in India: a population-based study. Kidney Int. 2006;70(12):2131-3.

3. Khakurel S, Agrawal RK, Hada R. Pattern of end stage renal disease in a tertiary care center. JNMA. 2009;48:126-30.

4. Shrestha SRK, Sigdel MR, Kafle MP, Shah DS. Renal transplant in Nepal: medical complications in first three months. J Inst Med. 2013;36:38-44.

5. Ranasinghe P, Perera YS, Makarim MF, Wijesinghe A, Wanigasuriya K. The costs in provision of haemodialysis in a developing country: A multi-centered study. BMC Nephrology. 2011;12:42. https://doi.org/10.1186/1471-2369-12-42.

6. Narva AS, Briggs M, Jordan R, Pavkov ME, Burrows NR, Williams DE. Toward a More Collaborative Federal Response to Chronic Kidney Disease. Adv Chronic Kidney Dis. 2010;17:282-8. https://doi.org/10.1053/j.ackd.2010.03.006.

7. Ojo A. Addressing the global burden of chronic kidney disease through clinical and translational research. Trans Am Clin Climatol Assoc. 2014;125: 229-43 discussion 243-226.

8. Parthasarathi G, Narahari M, Gurudev K, Sathvik B. An assessment of the quality of life in hemodialysis patients using the WHOQOL-BREF questionnaire. Indian J Nephrol. 2008;18:141. https://doi.org/10.4103/09714065.45288 
9. Mishra D, Koirala P. Status of Chronic Kidney Disease Patients Registered in National Kidney Center, Banasthali, Kathmandu. J Manmohan Memorial Inst Health Sci. 2015;1:19-23. https://doi.org/10.3126/jmmihs.v1i4.11997.

10. Karki KB, MJ GM, Pandey AR, Makai P, Subedi R, Poudyal A, Aryal KK. Assessment of Chronic Kidney Disease Support Program of Government of Nepal, 2016. Kathmandu: Nepal Health Research Council; 2017.

11. Khadka R, Basnet NB, Kafle RK Nutritional Status of Out-patient Hemodialysis Patients in a Hospital-based Hemodialysis Centre in Nepal. Nepalese Med J. 2018;1(1):12-6.

12. Sedhain A, Hada R, Agrawal RK, Bhattarai GR, Baral A. Assessment of nutritional status of Nepalese hemodialysis patients by anthropometric examinations and modified quantitative Subjective Global Assessment. Nutrition and metabolic insights. 2015;8:NMI. S27640.

13. Sigdel $M$, Pradhan $R$ : Chronic kidney disease in a tertiary care hospital in Nepal. J Inst Med. 2018;42(1):104-11.

14. Fox E, Peace K, Neale TJ, Morrison RB, Hatfield PJ, Mellsop G. quot;Quality of life\&quot; for patients with end-stage renal failure. Ren Fail. 1991;13:31-5.

15. Edgell ET, Coons SJ, Carter WB, Kallich JD, Mapes D, Damush TM, Hays RD. A review of health-related quality-of-life measures used in end-stage renal disease. Clin Ther. 18:887-938.

16. Testa MA, Simonson DC. Assessment of Quality-of-Life Outcomes. N E J Med. 1996:334:835-40. https://doi.org/10.1056/NEJM199603283341306.

17. SE K. The increasing importance of quality of life research. Clin Res 2001, 1:18-22.

18. Mapes DL, Lopes AA, Satayathum S, Mccullough KP, Goodkin DA, Locatelli F, Fukuhara S, Young EW, Kurokawa K, Saito A. Health-related quality of life as a predictor of mortality and hospitalization: the Dialysis Outcomes and Practice Patterns Study (DOPPS). Kidney int. 2003;64(1):339-49.

19. Muehrer RJ, Becker BN. PSYCHOSOCIAL FACTORS IN PATIENTS WITH CHRONIC KIDNEY DISEASE: Life After Transplantation: New Transitions in Quality of Life and Psychological Distress. Semin Dial. 2005;18:124-31. https://doi.org/10.1111/j.1525-139X.2005.18214.x.

20. Molnar-Varga M, Molnar MZ, Szeifert L, Kovacs AZ, Kelemen A, Becze A, Laszlo G, Szentkiralyi A, Czira ME, Mucsi I, et al. Health-Related Quality of Life and Clinical Outcomes in Kidney Transplant Recipients. Am J Kidney Dis. 2011:58:444-52. https://doi.org/10.1053/j.ajkd.2011.03.028

21. Unruh ML, Hess R. Assessment of Health-Related Quality of Life Among Patients With Chronic Kidney Disease. Adv Chronic Kidney Dis. 2007;14:34552. https://doi.org/10.1053/j.ackd.2007.07.011.

22. Dulal RK, Karki S. Nepalese kidney transplant recipient in a follow up clinic: related and unrelated living donor. JNMA. 2008;47:98-103.

23. Hirachan P, Kharel T, Shah DS, Ball J. Renal replacement therapy in Nepal. Hemodial Int. 2010;14:383-6. https://doi.org/10.1111/j.1542-4758.2010.00474.x.

24. Ministry of Health and Population. Medical Treatment of Underprivileged Citizens. 2020. https://www.mohp.gov.np/en/news/591-approved-meetingminute-of-2076-12-23-regarding-medical-treatment-of-underprivilegedcitizens. Accessed 4/20/2020.

25. World Health Organization Division of Mental Health: WHOQOL-BREF: introduction, administration, scoring and generic version of the assessment: field trial version, December 1996. 1996

26. Giri S, Neupane M, Pant S, Timalsina U, Koirala S, Timalsina S, Sharma S. Quality of life among people living with acquired immune deficiency syndrome receiving anti-retroviral therapy: a study from Nepal. HIV/AIDS (Auckland). 2013;5:277-82. https://doi.org/10.2147/HIV.S50726.

27. Mishra SR, Sharma A, Bhandari PM, Bhochhibhoya S, Thapa K: Depression and health-related quality of life among patients with type 2 diabetes mellitus: a cross-sectional study in Nepal. PLoS One. 2015;10(11):1-13.

28. Ghosh A, Ghosh T. Modification of Kuppuswamys socioeconomic status scale in context to Nepal. Indian Pediatr. 2009;46(12):1104-5.

29. Sapkota A, Sedhain A, Rai MK. Quality of life of adult clients on renal replacement therapies in Nepal. J Ren Care. 2013;39(4):228-35.

30. Rambod M, Shabani M, Shokrpour N, Rafii F, Mohammadalliha J. Quality of Life of Hemodialysis and Renal Transplantation Patients. Health Care Manager. 2011;30:23-8. https://doi.org/10.1097/HCM.0b013e3182078ab6.

31. Oh SH. Yoo EK: [Comparison of quality of life between kidney transplant and hemodialysis patients]. Taehan Kanho Hakhoe chi. 2006;36:1145-53.

32. Purnell TS, Auguste $P$, Crews DC, Lamprea-Montealegre J, Olufade T, Greer R, Ephraim P, Sheu J, Kostecki D, Powe NR, et al. Comparison of life participation activities among adults treated by hemodialysis, peritoneal dialysis, and kidney transplantation: a systematic review. Am J Kidney Dis. 2013;62:953-73. https://doi.org/10.1053/j.ajkd.2013.03.022.

33. Wyld M, Morton RL, Hayen A, Howard K, Webster AC. A Systematic Review and Meta-Analysis of Utility-Based Quality of Life in Chronic Kidney Disease
Treatments. PLoS Med. 2012;9:e1001307. https://doi.org/10.1371/journal. pmed.1001307.

34. Ogutmen B, Yildirim A, Sever M, Bozfakioglu S, Ataman R, Erek E, Cetin O, Emel A: Health-related quality of life after kidney transplantation in comparison intermittent hemodialysis, peritoneal dialysis, and normal controls. In: Transplantation proceedings: 2006. USA: Elsevier; 2006: 419-421.

35. Mcgee J, Pandey B, Maskey A, Frazer T, Mackinney T. Free dialysis in Nepal: Logistical challenges explored. Hemodial Int. 2018;22:283-9. https://doi.org/ 10.1111/hdi.12629.

36. Lowney AC, Myles HT, Bristowe K, Lowney EL, Shepherd K, Murphy M, O'Brien T, Casserly L, McQuillan R, Plant WD. Understanding what influences the health-related quality of life of hemodialysis patients: a collaborative study in England and Ireland. J Pain Symptom Manage. 2015;50(6):778-85.

37. Gerogianni S, Babatsikou F, Gerogianni G, Grapsa E, Vasilopoulos G, Zyga S. Koutis C: 'Concerns of patients on dialysis: A Research Study'. Health Sci J. 2014;8(4):423.

38. Joshi U, Subedi R, Poudel P, Ghimire PR, Panta S, Sigdel MR. Assessment of quality of life in patients undergoing hemodialysis using WHOQOL-BREF questionnaire: a multicenter study. Int J Nephrol Renovasc Dis. 2017;10:195203. https://doi.org/10.2147/IJNRD.S136522.

39. Gerogianni G, Lianos E, Kouzoupis A, Polikandrioti M, Grapsa E. The role of socio-demographic factors in depression and anxiety of patients on hemodialysis: an observational cross-sectional study. Int Urol Nephrol. 2018; 50(1):143-54.

40. Sayin A, Mutluay R, Sindel S: Quality of life in hemodialysis, peritoneal dialysis, and transplantation patients. In: Transplantation proceedings: 2007. USA: Elsevier; 2007. p. 3047-53.

41. Mishra SR, Khanal P, Karki DK, Kallestrup P, Enemark U. National health insurance policy in Nepal: challenges for implementation. Global health action. 2015;8(1):28763.

42. Pokharel R, Silwal PR. Social health insurance in Nepal: A health system departure toward the universal health coverage. Int J Health Plan Manage. 2018:33(3):573-80

43. International Labour Organization. Decent Work Country Progam 20132017. Kathmandu: ILO; 2013.

44. Sapkota T, Houkes I, Bosma H. Vicious cycle of chronic disease and poverty: a qualitative study in present day Nepal. Int Health. 2020:1-9.

45. Dhimal M, Karki KB, Sharma SK, Aryal KK, Shrestha N, Poudyal A, Mahato NK, Karakheti A, Sijapati MJ, Khanal PR. Prevalence of selected chronic noncommunicable diseases in Nepal. J Nepal Health Res Council. 2019;17(3): 394-401.

\section{Publisher's Note}

Springer Nature remains neutral with regard to jurisdictional claims in published maps and institutional affiliations.

Ready to submit your research? Choose BMC and benefit from:

- fast, convenient online submission

- thorough peer review by experienced researchers in your field

- rapid publication on acceptance

- support for research data, including large and complex data types

- gold Open Access which fosters wider collaboration and increased citations

- maximum visibility for your research: over $100 \mathrm{M}$ website views per year

At $\mathrm{BMC}$, research is always in progress.

Learn more biomedcentral.com/submission 